\title{
The Juan Linz Archive of the Spanish Transition to Democracy 1975-1983: A PROJECT OF ANALYSIS, DIGITALIZATION AND EVENT HISTORY DATABASE
}

\begin{abstract}
Under the directorship of Almudena Knecht, the Library of the Centre for Advanced Studies in the Social Sciences of the Juan March Institute is constructing a digital archive of some 65,000 articles from eleven Spanish newspapers that mirrors Spain's transition to democracy.
\end{abstract}

Spain's transition to democracy is one of the most cited cases of a successful and peaceful regime change of the twentieth century. It is a model studied and admired by the international community and imitated by a large number of countries in their own political reform process. The central object of this project is to provide a unique tool for the study of transitions to democracy, using as an example the Spanish case through the clipping archive selected and organized by Professor Juan Linz.

Professor Juan Linz, professor emeritus of Yale University, has donated his personal archive of press clippings from 1975 to the early ' 80 s from twelve Spanish newspapers, to the Library of the Centre of Advanced Studies in the Social Sciences of the Juan March Institute of Madrid. The fact that Professor Linz selected the articles gives the archive a mark of scholarly quality, which makes it a major research tool for students and practitioners of democratic transitions. Professor Linz's reputation as a scholar on transitions and as a mentor to hundreds of other scholars is well known. While his reputation encompasses studies beyond Spain's boarders, his studies and publications on Spain started in the '60s while Spain was still under the Francoist regime and continue to the present. Professor Linz's own words (1987) validate the importance of the project “... the years after the death of Franco were of uncertainty, ambivalence and risk. Neither political structure, nor any political model are sufficient to explain such a process without reference to the political actors that made the day by day decisions, confronting unexpected crisis that could have derailed the transition in spite of the well conceived and planned policies and procedures." This archive provides that ideal looking glass that reflects the dynamic and multi-faceted construction we call a "democratic transition".

The archive of over 60,000 articles is in such a delicate condition that the needs for its preservation conflicts directly with the corresponding need to make the archive
By Martha Peach*

available to researchers and students of transitions to democracy. The archive reflects the transition by covering every aspect of daily events, actors, public reactions, and the evolving network of decisions that brought Spain to a successful democratic transition. Using current technology the archive will be preserved and will be freely available on the Internet in the Centre's web page (www.march.es) with searching capability by a multitude of identifiers as well as full text searching. The articles will also be viewable and downloadable as a graphic image and they will be available as a text file.

Since we did not want to provide just a meta-data catalogue of the archive but rather provide a virtual archive with a catalogue and with enhanced searching and retrieval capabilities, we decided to include some new elements into the "tool box" of the archive's user interface. The most innovative element is the ability to use normalized fields as variables and thereby construct databases for event data analysis using SPSS or other statistical software. The normalized fields include register number of the article, author, name of newspaper, page, article length (represented by number of paragraphs), source of information (for example, government source, politician, church, etc.), date, descriptors, type of article (editorial, news, etc.), existence and type of graphic illustrations. Therefore a researcher wanting to do an analysis of newspaper coverage of a topic such as abortion could download the metadata of all articles that included the descriptor (or even the word "abortion", since there will be full text searching capabilities), then load the meta data into a data analysis program. By doing cross tab or other type of analysis the researcher would be able to do an analysis of volume of articles by date element or by newspaper or by type of article or by source of information used by the author of the article, etc. It is hoped that the researcher would also be able to click on the register number to retrieve the digital image or the text file, to enable confirmation of variables etc.

The project involves the development of five elements: a database registering each article, a thesaurus of descriptors, a graphic image archive, a text archive, searching screens with download, secondary analysis and printing 
capabilities. The major design work has been done with the collaboration of librarians, scholars, and computer technicians. The document analysis is being done by a team of research assistants with degrees in political science, contemporary history and library science. The digitalisation will be contracted out to a firm specializing in document processing. Librarians and computer technicians have developed the search and display software.

The final result of the project will enable scholars throughout the world to follow the Spanish transition, accessing primary documents as events unfold, see the succession of events as decisions were made, and construct statistical analysis of trends. Theories and models of the Spanish transition can be exposed as never before to the documental reality of the events as they happened. Historical memory can be juxtaposed against events as reported by the Spanish press. Textual analysis that can illuminate the role and behaviour of the press will be facilitated by the archive. The project will be a model for archives of other transitions and political events. And lastly, the software, thesaurus and procedures employed by the project can easily be transferred for use by projects of similar purpose. Thanks to advances in telecommunication technology, the project's importance also incorporates several innovations in digital archives. These innovations respond to researchers' needs both for qualitative analysis as well as macro statistical analysis of trends, patterns and agenda setting reflected in the Spanish press during the transition.

The Project to date has received more than $150,000 €$ in grants from the Spanish Ministry of Education, Culture and Sports and the Spanish Ministry of Science and Technology and the Community of Madrid. The Juan March Institute has supported the project with computer equipment, computer support and the librarians of the Institute have been directing the design and processing elements of the Project. Scholars associated with the Institute have assisted in the design of the project as well as helping search for funding. The European Program Leonardo has provided two researchers for five months each. The Library Schools of SEDIC, Carlos III of Madrid and the Complutense University has provided other researchers.

The design work and the infrastructure of the project are open ended in that it can be applied to other archives. It is hoped that the project will generate spin-off projects that will expand the coverage of the Spanish transition as seen in the press of other countries as well as reflected in other archives of interviews, personal archives of people of the transition, etc. Much of the design work is also applicable for treatment of similar archives of other regime transitions.

The final goal of the project is to offer to the international research community an Internet archive and user interface that will enable studies heretofore possible only with great expense of time and effort and will be a tool to test existing hypothesis and conclusions concerning democratic transitions as well as possibly generating new avenues of research.

\section{Reference}

Juan Linz. 1987. "Innovative Leadership in the Transition to Democracy and a New Democracy: The Case of Spain." Draft paper prepared for discussion at the Conference on "Innovative Leadership and International Politics" of the Leonard Davis Institute for International Relations, Hebrew University, Jerusalem, June 8-10, 1987. pp. 1-2.

* Martha Peach, Director of the Library, Centre for Advanced Studies in the Social Sciences, Juan March Institute, Madrid, Spain, Peach@ceacs.march.es 